Research

\title{
DEMs and reliable sea level rise risk monitoring in Nile Delta, Egypt
}

\author{
Tarek Abdel-Aziz ${ }^{1} \cdot$ Gomaa Dawod $^{1}$ (D) $\cdot$ Hala Ebaid $^{1}$
}

Received: 17 September 2020 / Accepted: 19 November 2020

(c) The Author(s) 2020 OPEN

\begin{abstract}
This research aims to evaluate the accuracy and reliability of utilizing global Digital Elevation Models (DEMs) in risk monitoring of Sea Level Rise (SLR) in the Nile delta region, Egypt. Such a Geographic Information Systems (GIS)-based assessment process has been carried out using high-precision terrestrial surveys to develop a new local DEM (named SRI18) to precisely identify possible inundated areas by 2025. The presented DEM comparison approach has been performed based on spatial distribution rather than the traditional point-wise method. Based on novel proposed evaluation indicators, it has been found that the reliability of three investigated global models (namely: SRTM1, ASTER, and EarthEnvi-DEM90), in delineating sea level rise flooded areas, is less than $20 \%$. Hence, it is concluded that the utilization of global DEMs may not be optimum in the planning and management of coastal areas in the Nile delta region. Such a methodology could be applied in other low-lying deltaic areas worldwide for investigating GDEMs reliability for SLR monitoring and assessment in coastal regions.
\end{abstract}

Keywords DEM · Sea level rise $\cdot$ Risk monitoring $\cdot$ GIS $\cdot$ Nile delta

\section{Introduction}

Natural hazards cause significant damages, kill thousands of people, and seriously affect the sustainability of natural and human resources worldwide. Successful thought, management, and reduction of risks from natural hazards is an interdisciplinary field of risk monitoring and analysis that relies upon collecting heterogeneous precise datasets. Geomatics technologies, particularly satellite-based positioning, remote sensing and Geographic Information Systems (GIS), play a crucial role in data gathering, visualization, and analysis of natural hazards risks. On a sense, sea level rise is considered as one of the most severe natural hazards threatening coastal zones all over the world in the last few decades.

It is a matter of fact that sea level has been recently rising as a vital sequence of global warming and climate changes phenomena. Sea Level Rise (SLR) might be attributed mostly to greenhouse effects and the melting of glaciers and polar ice sheets. SLR constitutes one of the most noteworthy challenges facing the world mainly in coastal zones and low-lying deltaic areas. Globally, the sea level has been considerably raised in the twentieth century with reported rates equal to 1.5 for 1901-1990, 2.0 for 1971-2010, and $3.2 \mathrm{~mm} /$ year for 1993-2010 [1]. Furthermore, the anticipated global sea level in 2081-2100 range from 0.40 to $0.63 \mathrm{~m}$ relative to the 1986-2005 level (ibid). Recent estimates of global SLR indicated that its rising rate is more than doubled throughout most of the twentieth century and it may reach $0.3 \mathrm{~m}$ above the 2000 levels by 2100 [2]. As a result, it is expected that 190 million capita could be subjected to coastal flooding worldwide by 2100 since they occupy global land below the projected high tide lines [3]. In this regard, it worth mentioning that several research studies have stated that Alexandria city in Egypt is considered one of twenty cities worldwide that are most exposed to hazardous natural risks particularly due to coastal

Gomaa Dawod, dawod_gomaa@yahoo.com | 'Survey Research Institute National Water Research Center, Giza, Egypt.

Discover Sustainability $\quad$ | (2020) 1:6 Ittps://doi.org/10.1007/s43621-020-00006-7 
flooding by 2070 [4]. On another sense, the rise of sea level could impact coastal regions in several hazardous ways including the increase of the frequency and severity of coastal flooding, increasing the length and energy of waves, increasing the salinity of groundwater, and raising the groundwater surface elevation [5].

Nationally, sea level rise determination and the assessment of its impacts in Egypt have been investigated broadly in the last few decades. For example, Mohamed [6] analyzed tide gauge records at Alexandria from 1906 to 2003 and estimated the absolute sea level rise rate as $2.3 \mathrm{~mm} /$ year. Additionally, [7] applied altimetry dataset 1993-2013 to assess the relative sea level rise rate at the Egyptian Mediterranean coast, and found the rise rate is $3.1 \mathrm{~mm} /$ year. Between 1926 and 2000, the absolute sea level rise has been computed at Port Said as $2.3 \mathrm{~mm} /$ year [8]. Recently, [9] have figured out that the confidential relative sea level rise estimates in the Nile delta region, between 1990 and 2016, vary from 2.6 to $4.3 \mathrm{~mm} /$ year, while the absolute sea level rise rates differ between $5.0 \mathrm{~mm} /$ year at Alexandria to $6.9 \mathrm{~mm} /$ year at Port Said.

Several hazardous impacts of sea level rise have been investigated worldwide, particularly in low-land deltas, which necessitate the development of risk assessment adaptation planning (e.g. [10]). Examples of such hazardous impacts include the increase of urban flood probability e.g. [11], alteration of freshwater management and water quality (e.g. [12]), shorelines retreat, dune replacement, and residential resilience in coastal areas (e.g. [13]), and harmful changes of groundwater quality in coastal regions due to seawater intrusion (e.g. [14]). Geographic Information Systems (GIS) have been extensively applied, as cost-effective and efficient technical tools, in monitoring the sea level rise effects worldwide (e.g. [15]).

A Digital Elevation Model (DEM) is a three-dimensional digital representation of the Earth topography. Generally, DEM can be developed from a wide range of source datasets such as terrestrial field surveys, topographic contour maps, overlapped aerial photographs or satellite imageries, and airborne or satellite-based radar remote sensing measurements. Additionally, global DEMs (GDEMs) have been developed and released on a global basis in the last few decades. In Egypt, DEMs have been utilized in numerous researches and development projects such as: monitoring the subsidence of the Nile delta (e.g. [16]), monitoring land degradation (e.g. [17]), determination of hydro-morphological characteristics and assessment of flash flood potentially (e.g. [18]), and the potential sea level rise impacts on the Nile delta (e.g. [19]).

Delineation of SLR-induced inundated regions depends generally upon the accuracy of elevation information utilized in such an assessment. Accordingly, many research studies have been carried out to judge the accuracy and reliability of DEMs in geomatics and environmental applications in general and particularly in SLR impact assessment. For example, Dawod and Al-Ghamdi [20] have examined the accuracy of eight open-source global DEMs in Egypt and Saudi Arabia using terrestrial ground control points. The obtained results showed that the standard deviations of GDEMs range from \pm 1.9 to $\pm 6.7 \mathrm{~m}$ over both regions. In addition, Global Positioning System (GPS)-based control points have been utilized to evaluate the accuracy of several global DEM models and have produced a comparable level of accuracy (e.g. [21]). In the same context, other research studies (e.g. [22, 23]) have figured out that the overall accuracy of GDEMs is in the order of a few meters. Similarly, it has been concluded that GDEMs are not the optimum source of elevations for flood risk assessment particularly for low-lying deltaic areas [24]. Hence, it could be concluded that GDEMs might be appropriate for planning and small-scale environmental studies but not optimum for coastal planning nor engineering projects. It worth mentioning that recent studies emphasized the utilization of local precise DEM for truthful monitoring and analyzing the potential impacts of SLR [25].

In Egypt, Ministry of Water Resources and Irrigation (WRI) has initiated a huge project for the adaptation to climate change in the Nile delta through integrated coastal zone management. An important requirement in this project was the development of a high-resolution high-accuracy DEM for the Nile delta coastal region for future coastal management activities. That part was assigned to the Survey Research Institute (SRI) of the National Water Research Center (NWRC). The developed local DEM was based on the utilization of GPS and terrestrial precise levelling datasets that cover the area from the shoreline to almost $1 \mathrm{~km}$ perpendicular to it. It has been concluded that such a $1.3 \mathrm{~s}$ spatial resolution DEM has a vertical accuracy of $5 \mathrm{~cm}$ approximately [26].

In the context of seal level rise hazard monitoring, several researches and even practical projects depend on the utilization of global DEMs in Egypt and other countries. It is a matter of reality that estimating the vertical accuracy of a local or global DEM is an essential aspect before its actual applications since the quality of a DEM affects the results of its application [27]. The current study investigates in details the accuracy and reliability of GDEMs for coastal environmental applications in general and for SLR monitoring in particular. Rather than the point-wise evaluation of GDEMs' vertical accuracy, this paper provides a novel approach of using several models with variable spatial resolution and 
vertical accuracy for the accurate monitoring and assessment of sea level rise impacts in the Nile delta coastal areas. The expected findings would be crucial for decision makers not only in Egypt but also in other regions of low-lying deltas.

\section{Study area and materials}

The investigated coastal study area within the Nile delta coasts on the Mediterranean Sea sector extends from longitude $29.8^{\circ} \mathrm{E}$ to longitude $32.3^{\circ} \mathrm{E}$, and from latitude $31.2^{\circ} \mathrm{N}$ to latitude $31.6^{\circ} \mathrm{N}$ (Fig. 1). With more than 50 million populations, the Nile delta might be considered as one of the most densely populated regions worldwide. In addition, it suffers from several environmental problems affecting the sustainable management of natural resources, such as saltwater intrusion, shoreline erosion, and land subsidence. The study area extends in the east-west direction over $273 \mathrm{~km}$ from Port Said at the east to Alexandria at the west, with approximately more than one kilometer perpendicular to the shoreline. The overall area of that region equals about 317 square kilometers. Types of land use over the study area have been extracted from TripleSat $\mathrm{m}$ spatial-resolution satellites imageries (Fig. 2). They have been verified by field campaigns utilizing GPS equipment [26]. Table 1 presents statistics about existing land uses, from which it can be noticed that the undeveloped areas cover almost 70\% from the entire study area. Over this area, terrestrial field campaigns have been carried out to develop a new local high-precision high-resolution DEM. The observation strategy has combined Global Navigation Satellite Systems (GNSS) measurements with precise levelling. First, a geodetic control network has been established with 5-km spacing. Second, an MSL-based orthometric height for every control point has been determined through precise levelling routes to the nearest Bench Mark (BM). Third, a Post-Processing Kinematic (PPK) GNSS has been implemented in topographic surveying of the entire undeveloped areas. Therefore, about 184 thousands GNSS/ Levelling points have been measured to create a local DEM and produce contour maps. The spatial resolution of the attained DEM estimated as $1.3 \mathrm{~s}$ [26].

Dawod et al. [9] have investigated relative and absolute sea level rise at the Nile delta area based on tide gauge records and GNSS-based datasets. That study concluded that the absolute sea level rise differs between $5.0 \mathrm{~mm} / \mathrm{year}$ at Alexandria to $6.9 \mathrm{~mm} /$ year at Port Said, and the mean sea level will be raised about 17 and $23 \mathrm{~cm}$ at Alexandria and Port Said respectively by year 2025. Such results have been considered the basis in the current research to compare the performance of several DEMs in monitoring and assessing sea rise impacts.

Additionally, three Global DEM models (GDEMs) have been utilized in the current study, namely the Shuttle Radar Topography Mission (SRTM), EarthEnv-DEM90, and the Advanced Spaceborne Thermal Emission and Reflection Radiometer (ASTER). SRTM is a global DEM that has two versions: SRTM1 with a spatial resolution of 1 arc-second, i.e., approximately $30 \mathrm{~m}$, and SRTM3 model with a 3 arc-second resolution (download from e.g. https://earthexplorer.usgs.gov/). The SRTM1 version is utilized herein. On the other hand, ASTER is 1 arc-second global DEM. The ASTER version 2 has been publically released in 2011 (download from e.g. https://asterweb.jpl.nasa.gov/gdem.asp). Additionally, the EarthEnvDEM90 is a 3-arc-second global DEM derived from processing and merging SRTMv4 and ASTER v2 data products to provide continuous coverage of $91 \%$ of the globe (download from http://www.earthenv.org/DEM). These three GDEMs have been selected for several reasons; first, they produce a high-reliability index, exceeded 7 out of 10, in the Nile delta

Fig. 1 Study area

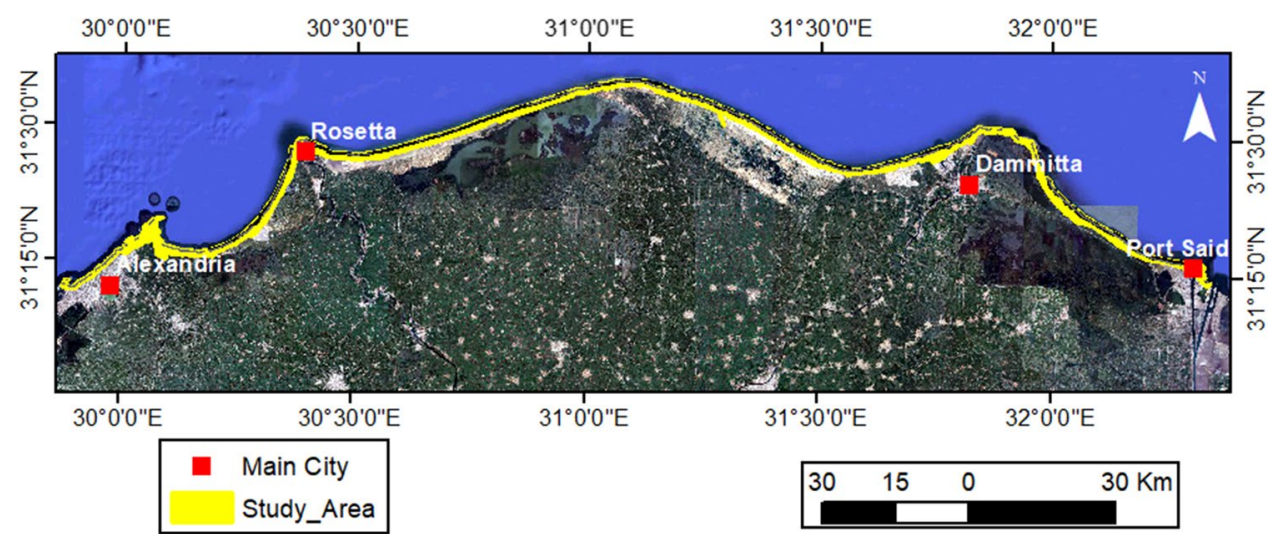


Fig. 2 Land uses at main cities
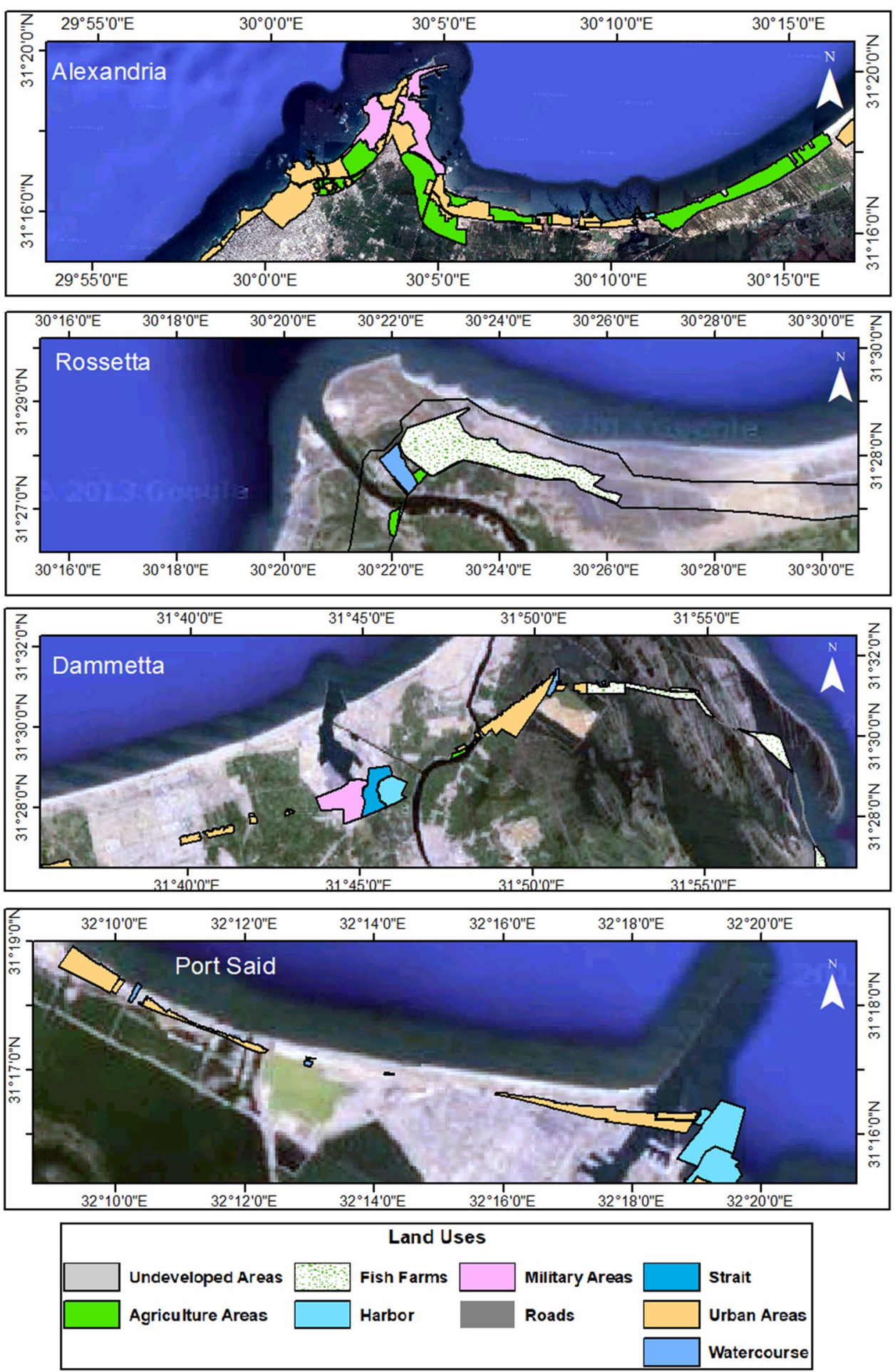

area as reported by [20]. Second, they represent different spatial resolutions ( 1 and 3 arc seconds) which would help assessing the sensitivity and precision of GDEMs to spatial variations in the process of SLR impact monitoring (e.g. [17]). Third, the SRTM1 and ASTER have been widely utilized in risk assessment due to sea level rise in Egypt [e.g. [28, 29]] and worldwide (e.g. [30, 31]). Lastly, they are open-source free-accessible topographic models with enhanced more-accurate versions periodically. 
Table 1 Land uses in the study area

\begin{tabular}{lcc}
\hline Type & Total area $\left(\mathrm{km}^{2}\right)$ & $\%$ of areas \\
\hline Undeveloped areas & 221.95 & $69.9 \%$ \\
Urban areas & 33.736 & $10.6 \%$ \\
Fish farms & 26.579 & $9.8 \%$ \\
Agriculture areas & 17.957 & $6.6 \%$ \\
Military areas & 8.759 & $3.2 \%$ \\
Harbor & 4.620 & $1.7 \%$ \\
Strait & 1.793 & $0.7 \%$ \\
Watercourse & 1.580 & $0.6 \%$ \\
Roads & 0.474 & $0.2 \%$ \\
Total & 317.448 & $100 \%$ \\
\hline
\end{tabular}

\section{Methodology and processing}

The traditional method for evaluating GDEMs, presented in several research works, depends on the point-wise evaluation of a model over some known ground checkpoints and comparing the attained results through some statistical indicators (e.g. [20, 22, 23]). However, such a scheme might not be the optimum one dealing with SLR impact assessment that depends on spatial extents over a geographic area. Accordingly, the current research presents an innovative plan comprising several steps for manipulating and processing local and global DEMs over the study area within a GIS environment (Fig. 3). The central constituent of such a system is the utilization of GPS and terrestrial precise levelling datasets to depict accurately the topography of the coastal area with a few-centimeter level of precision. This high-precision level enables accurate estimation of SLR-based inundated regions and, subsequently, truthful estimation of GDEMs corresponding results and reliability. That methodology could be applied in other low-lying deltaic areas worldwide for investigating GDEMs reliability for SLR monitoring and assessment in coastal regions.

Starting with the observed 184 thousand GNSS/Levelling points, a local precise DEM, called SRI18-DEM, has been developed. Additionally, four contour maps, regarding the four utilized DEMs, have been generated using the 3D analyst tools. An overall statistical and spatial analysis of those models has been performed. On a pixel-by-pixel basis, the EarthEnv-90 model produces a smaller range of variations to SRI18 local model. Such variation differences amount to

Fig. 3 Data processing steps

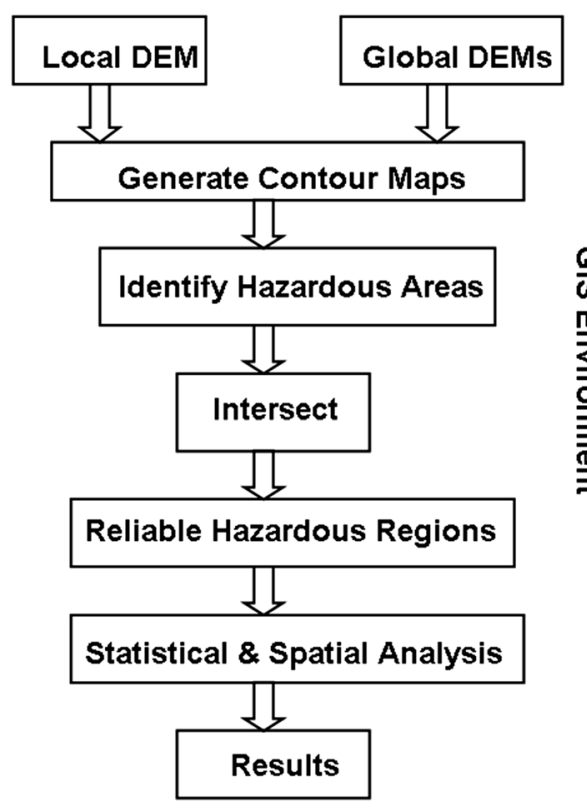


almost $50 \%$ of the corresponding differences of both SRTM 1 and ASTER GDEMs when compared to SRI18 model. This might be attributed to the fact that EarthEnv-DEM90 model has been derived from efficient new processing and merging SRTMv4 and ASTER v2 data products. These two results give an overall view of the performance of utilized global models. However, detailed investigations are still needed particularly regarding the hazardous effects of SLR.

Next, the recent estimate of SLR in the study area as reported by [9] has been adopted in the current research since they represent the most recent local SRL estimates in Egypt. Hence, an overall rise of $0.25 \mathrm{~m}$ is anticipated by the year 2025. The method utilized in this study is based on the determination of contour line corresponds to the anticipated SLR. Then, the areas surrounded by the zero contour (current sea level) and that contour would represent the expected inundated regions due to SRL rise by 2025. Consequently, the differences between contour lines zero and $0.25 \mathrm{~m}$ have been identified as hazardous areas. Subsequently, the total areas of these regions have been computed and analyzed for all cases. Table 3 presents the statistics concerning the utilized DEMs, which indicates some main findings. Such results only present quantitative measures regarding the precision of several DEM models with varying levels of accuracy and spatial resolution. A spatial perspective is still desired for accurate mapping of inundated regions due to SLR utilizing the ArcGIS 3D analysis and spatial analysis tools. Since the local DEM is accurate, the overlapped parts of the hazardous areas between the local model and a particular global model could be considered as a truth index for that model. A novel reliability index has been introduced, in this study, to differentiate between the performances of the utilized models. Statistical and spatial analyses have been performed to investigate the accomplished results as shown in the next section.

\section{Results and discussions}

Monitoring SLR-based inundated regions depends on the accuracy of elevation information utilized in such an assessment. While the classical method for evaluating GDEMs relies upon the point-wise evaluation of a model over some known ground checkpoints, the present study provides a new scheme for manipulating and processing local and global DEMs. The local SRTM18 DEM represents the basis of such evaluation due to its high accuracy in depicting the topography of the study area within few-centimeters accuracy level. The overall statistical measures of the investigated models and the deviations between them over the study area are presented in Table 2. It can be noticed, from this table, that the EarthEnv-90 GDEM produced smaller range, averages, and standard deviation values compared to the SRTM 1 model. Moreover, it can be noticed that the ASTER model produce the worst results over the study area. Similar results have been reported by other researchers (e.g. [20]). Figure 4 depicts the anticipated inundated regions, between levels 0 and 0.25, using the SRI18, EarthEnv-90, SRTM1, and ASTER models respectively. From SRI18 results, it has been found that the anticipated inundated regions vary in width between 30 and $250 \mathrm{~m}$, with an average of $140 \mathrm{~m}$ approximately. These regions are spatially distributed almost over about $195 \mathrm{~km}$ of the shorelines that constitute about $70 \%$ of the study area coastlines. Such hazardous regions need to be considered for future development adaptation of sea level rise in the Nile delta.

A visual comparison between Fig. 4 clearly indicates the differences in delineating vulnerability areas obtained from the three digital elevation models. In addition, the total areas of these regions have been computed in all cases. Table 3 indicates some main findings. First, the total area of inundated regions due to sea level rise in the study area equals

Table 2 Statistics of DEMs over the study area $(\mathrm{m})$

\begin{tabular}{llllll}
\hline DEM & Minimum & Maximum & Range & Mean & $\begin{array}{l}\text { Standard } \\
\text { deviation }\end{array}$ \\
\hline Heights & & & & & \\
SRI18 & -2 & 17 & 19 & 1.35 & 1.49 \\
EarthEnv-90 & -5 & 23 & 28 & 0.88 & 2.17 \\
SRTM 1 & -24 & 59 & 83 & 1.36 & 3.69 \\
ASTER & -13 & 74 & 87 & 7.37 & 6.29 \\
Differences & & & & & \\
SRI18-EarthEnv-90 & -15 & 15 & 30 & 0.34 & 2.05 \\
SRI18-SRTM 1 & -43 & 17 & 60 & 0.33 & 3.43 \\
SRI18-ASTER & -62 & 12 & 74 & -6.26 & 5.66 \\
\hline
\end{tabular}



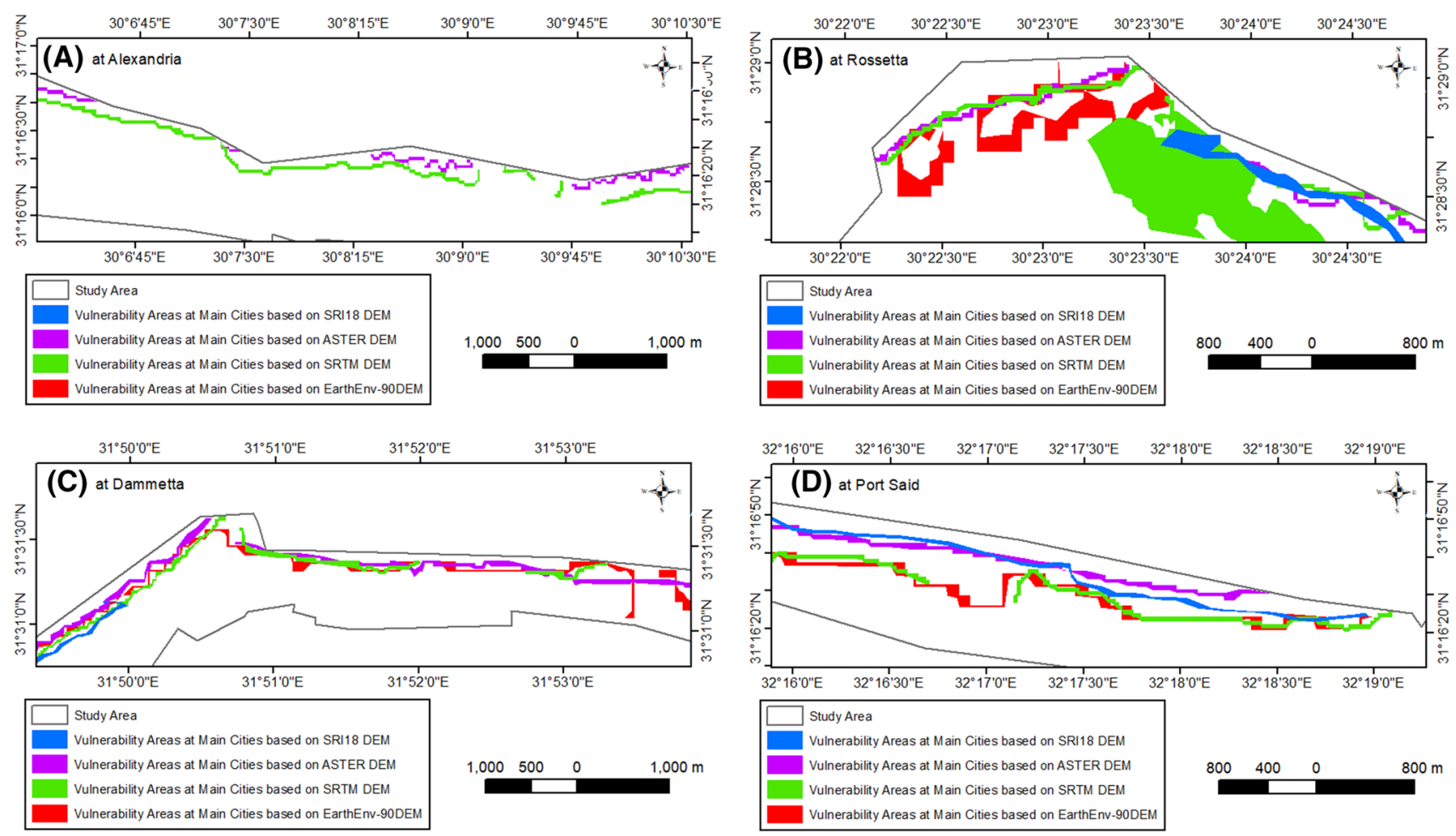

Fig. 4 Examples of vulnerability areas at main cities based on local and global DEMS

10.69 square kilometers that constitute just $4.8 \%$ of the undeveloped region. This represents a confident estimate when compared to results of previous researches that anticipated that the flooded areas could reach $49 \%$ of the Nile delta by the year 2100 under different scenarios of SLR (e.g. [18]). Compared to the local SRI18-DEM, the EarthEnv-90DEM model has exaggerated the anticipated inundated regions by approximately $111 \%$. Second, the SRTM1, ASTER models produced about $79 \%$ and $74 \%$ of the regions given by the SRI18-DEM respectively. These two points highlight the significant discrepancies between local accurate DEM and global DEMs, particularly in development plans of coastal areas due to sea level rise.

Figure $5 \mathrm{a}-\mathrm{c}$ represent examples of inundated regions over the study area based on several DEMs. The local SRI18 DEM has been chosen as the comparison bases since it represents the most accurate topography of the study area (just a few centimeters) for the first time in Egypt. This comparison demonstrates the reliability of each utilized GDEM in delineating the spatial distribution of its corresponding flooded regions compared to the truthful SRI18-DEM results. It can be noticed that the flooded areas resulting from global DEMs do not lie exactly on the corresponding locations from the local DEM. Therefore, it can be concluded that the total areas of inundated regions cannot be considered as an optimum measure of the global DEMs performances regarding the SLR impacts. Thus, the current study proposes the utilization of a novel index to represent the reliability of GDEMs in SLR monitoring and impact assessment. The proposed truth index, simply, equals the percentage of the intersected regions for each global model compared to the local accurate model. This approach has been applied for the three utilized GDEM, and the results are given in Table 4. It can be noticed, from this table, that the three GDEMs identify very small portions of the actual inundated regions resulted from the accurate local DEM. Therefore, the truth index for EarthEnv-90, SRTM1, and ASTER models equal $0.12,0.09$, and 0.10 respectively. The amplification percentage and the truth index (Tables 3 and 4) differ a little for each global DEM. So, a unique reliability index is introduced, herein as the result of dividing the amplification index by the corresponding truth index for each model. The values of that reliability index are shown in the last column of Table 4. From this table, it can be concluded that the investigated three GDEMs have a reliability index of $11 \%, 11 \%$, and $13 \%$ for EarthEnv-90, SRTM1, and ASTER respectively. Hence, it can be said that the reliability of the three global models in delineating sea level rise flooded areas is less than $20 \%$. The low-reliability of GDEMs could be attributed to several factors, including the date of their data collection, their spatial resolution, their accuracy in delineating shorelines, and the rapid undergoing shoreline retreat of 
Fig.5 Examples of inundated areas delineated from several DEMs
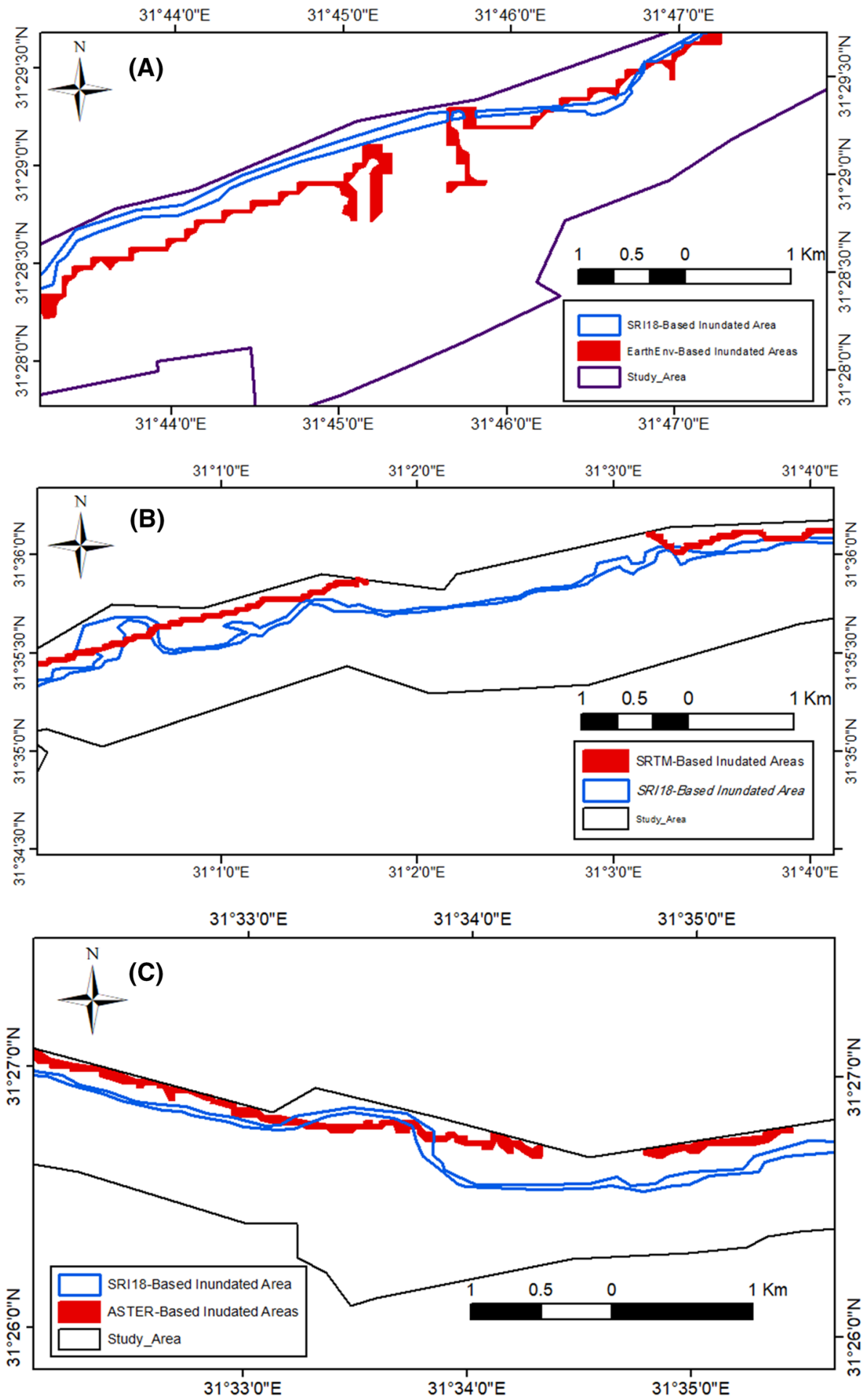

the Nile delta. Similarly, other researchers have stressed that a high-resolution high-accuracy DEM is crucial to attaining accurate results in environmental monitoring applications (e.g. [32]). It can be concluded that the accomplished findings herein are superior to those of previous studies in the Nile delta region due to the utilization of the local high-accuracy DEM for the first time in Egypt. It is a matter of reality that accurate topographic representation through a DEM model results in more accurate estimates of SLR impacts. 
Table 3 Statistics of vulnerability areas due to SLR

\begin{tabular}{lllll}
\hline DEM & Minimum area $\left(\mathrm{km}^{2}\right)$ & Maximum area $\left(\mathrm{km}^{2}\right)$ & Total area $\left(\mathrm{km}^{2}\right)$ & $\begin{array}{l}\% \text { of } \\
\text { amplifi- } \\
\text { cation }\end{array}$ \\
\hline SRI-18 & 0.059 & 6.828 & 10.690 & NA \\
EarthEnv-90 & 0.019 & 0.913 & 11.834 & $111 \%$ \\
SRTM 1 & 0.001 & 1.249 & 8.490 & $79 \%$ \\
ASTER & 0.001 & 1.572 & 7.930 & $74 \%$ \\
\hline
\end{tabular}

\begin{tabular}{llll}
\hline DEM & Sum of overlapped area $\left(\mathrm{km}^{2}\right)$ & Truth index & $\begin{array}{l}\text { Reli- } \\
\text { ability } \\
\text { index }\end{array}$ \\
\hline SRI-18 & NA & NA & NA \\
EartEnv-90 & 1.484 & $12 \%$ & 11 \\
SRTM 1 & 1.128 & $9 \%$ & 11 \\
ASTER & 1.233 & $10 \%$ & 13 \\
\hline
\end{tabular}

Table 4 Intersection between local and global DEM

\section{Conclusions}

Coastal management and risk monitoring of sea level rise necessitate accurate datasets describing spatial variations of the coastal topography. The digital elevation model is an optimum digital representation of topography and it constitutes a major element in coastal development. Rather than the traditional method for evaluating DEMs that relies upon pointwise evaluation of a model over some known ground checkpoints, the current research presents a new plan embracing several steps for manipulating and processing local and global DEMs over the study area within a GIS environment. The current research investigates the accuracy and reliability of some global DEMs over the Nile delta coastal region, namely EarthEnvi-90, SRTM1, and ASTER. Such an evaluation has been carried out based on a local accurate DEM of the area generating from terrestrial GPS/levelling surveying of about 300 square kilometers. It worth mentioning that results of local DEM reveal that the anticipated inundated regions vary in width between 30 and $250 \mathrm{~m}$, with an average of $140 \mathrm{~m}$ approximately. These regions are spatially distributed almost over about $195 \mathrm{~km}$ of the shorelines, which constitute about $70 \%$ of the study area coastlines. Such hazardous regions need to be considered for future development adaptation of sea level rise in the Nile delta.

Attained results highlighted that the flooded areas resulting from free global DEMs differ significantly from the corresponding areas resulting from local DEM, not just in total amount but also in spatial distribution. In addition according to the proposed indices for investigating the trustworthiness of DEMs, it has been concluded that the reliability of the three global models in delineating sea level rise flooded areas is less than $20 \%$. Such findings play a major role for decision-makers to avoid the utilization of global DEM models in the accurate planning and integrated management of coastal areas in the Nile delta region. Based on available datasets, the accomplished results stress that a local accurate and up-to-date terrestrial DEM is a must for precise risk assessment of sea level rise in Egypt and other developing countries. The proposed methodology could be applied in other low-lying deltaic areas worldwide for investigating GDEMs reliability for SLR monitoring and analyzing in coastal regions.

Authors' contributions All authors have made substantial contributions and have agreed with the content of the manuscript.

Funding There is no funding for this research.

Conflict of interest No potential conflict of interest was reported by the authors.

Open Access This article is licensed under a Creative Commons Attribution 4.0 International License, which permits use, sharing, adaptation, distribution and reproduction in any medium or format, as long as you give appropriate credit to the original author(s) and the source, provide a link to the Creative Commons licence, and indicate if changes were made. The images or other third party material in this article 
are included in the article's Creative Commons licence, unless indicated otherwise in a credit line to the material. If material is not included in the article's Creative Commons licence and your intended use is not permitted by statutory regulation or exceeds the permitted use, you will need to obtain permission directly from the copyright holder. To view a copy of this licence, visit http://creativecommons.org/licenses/by/4.0/.

\section{References}

1. Church J, Clark P, Cazenave A, Gregory J, Jevrejeva S, Levermann A, Merrifield M, Milne G, Nerem R, Nunn P, Payne A, Pfeffer W, Stammer D, Unnikrishnan A. Sea Level Change. In Climate Change 2013: The Physical Science Basis. Contribution of Working Group I to the Fifth Assessment Report of the Intergovernmental Panel on Climate Change (IPCC). Cambridge, UK: Cambridge University Press; 2013.

2. Lindsey, R. Climate change: Global sea level, 2020; https://www.climate.gov/news-features/understanding-climate/climate-change-globa I-sea-level, Accessed 25 Oct 2020.

3. Kulp S, Strauss B. New elevation data triple estimates of global vulnerability to sea-level rise and coastal flooding. Nat Commun. 2019. https://doi.org/10.1038/s41467-019-12808-z.

4. Siegel F. Adaptations of coastal cities to global warming, sea level rise, climate change and endemic hazards. Switzerland : Springer Briefs in Environmental Science; 2020. (10.1007/978-3-030-22669-5_7).

5. Raymond C, Conway-Cranos L, Morgan H, Faghin N, Spilsbury Pucci D, Krienitz J, Miller I, Grossman E, Mauger G. Sea level rise considerations for near-shore restoration projects in Puget Sound. A report prepared for the Washington Coastal Resilience Project. USA: University of Washington; 2018. https://cig.uw.edu/wp-content/uploads/sites/2/2018/11/Raymondetal_SLR_Restoration_2018_Compressed.pdf. Accessed Oct 2020.

6. Mohamed H. Realization and redefinition of the Egyptian vertical datum based on recent heterogeneous observations. Ph.D. diss. Egypt: Faculty of engineering at Shoubra, Benha university; 2005.

7. Shaltout $M$, Tonbol K, Omstedt A. Sea-level change and projected future flooding along the Egyptian Mediterranean coast. Oceanologia. 2015. https://doi.org/10.1016/j.oceano.2015.06.004.

8. Frihy O. Evaluation of future land-use planning initiatives to shoreline stability of Egypt's northern Nile delta. Arab J Geosci. 2017. https ://doi.org/10.1007/s12517-017-2893-4.

9. Dawod G, Mohamed H, Haggag G. Relative and absolute sea level rise based on recent heterogeneous geospatial data: a case study in the Nile delta Egypt. Sci Eng Res. 2019;6:55-64.

10. Abutaleb K, Mohammed A, Ahmed M. Climate change impacts, vulnerabilities and adaptation measures for Egypt's Nile delta. Earth Syst Environ. 2018. https://doi.org/10.1007/s41748-018-0047-9.

11. Griffiths J, Zhu F, Chan F, Higgitt D. Modelling the impact of sea-level rise on urban flood probability in SE China. Geosci Front. 2018. https ://doi.org/10.1016/j.gsf.2018.02.012.

12. Dessu S, Price R, Troxler T, Kominoski J. Effects of sea-level rise and freshwater management on long-term water levels and water quality in the Florida Coastal Everglades. Environ Manage . 2018;211:164-76.

13. Grilli A, Spaulding M, Oakley B, Damon C. Mapping the coastal risk for the next century, including sea level rise and changes in the coastline: application to Charlestown RI, USA. Nat Hazards. 2017;88:389-414.

14. Wassef R, Schüttrumpf H. Impact of sea-level rise on groundwater salinity at the development area western delta Egypt. Groundw Sustain Dev . 2016;2-3:85-103.

15. Ghoussein Y, Mhawej M, Jaffal A, Fadel A, El Hourany R, Faour G. Vulnerability assessment of the South-Lebanese coast: a GIS-based approach. Ocean Coast Manag. 2018;158:56-63.

16. El Bastawesy $M$, Cherif O, Sultan M. The geomorphological evidences of subsidence in the Nile Delta: analysis of high resolution topographic DEM and multi-temporal satellite images. Afr Earth Sci. 2017. https://doi.org/10.1016/j.jafrearsci.2016.10.013.

17. Kotb M, Ali R, El Semary M. Use of remote sensing and GIS for land degradation assessment of Qarun lake coastal area, EI-Fayoum, Egypt, In: Water and Land Security in Dry lands. 2017. https://doi.org/10.1007/978-3-319-54021-4_22.

18. Wahid A, Madden M, Khalaf F, Fathy I. Geospatial analysis for the determination of hydro-morphological characteristics and assessment of flash flood potentiality in arid coastal plains: a case study in southwestern Sinai, Egypt. Earth Sci Res. 2016. https://doi.org/10.15446/ esrj.v20n1.49624.

19. Hassan M, Adrabo M. Vulnerability of the Nile delta coastal areas to inundation by sea level rise. Environ Monit Assess. 2013;185:6607-16. https://doi.org/10.1007/s10661-012-3050-x.

20. Dawod G, Al-Ghamdi K. Reliability of recent global digital elevation models for geomatics applications in Egypt and Saudi Arabia. Geog Inform Syst. 2017;9:685-98.

21. Rawat K, Sing S, Singh M, Garg B. Comparative evaluation of vertical accuracy of elevated points with ground control points from ASTER DEM and SRTM DEM with respect to CARTOSAT-1 DEM. Remote Sens Appl Soc Environ. 2019;13:289-97.

22. Wang X, Holland D, Gudmundsoon H. Accurate coastal DEM generation by merging ASTER GDEM and IGESat GLAS data over Mertz glacier Antarctica. Remote Sens Environ. 2018;206:218-30.

23. Rabah M, El-Hattab A, Abdallah M. Assessment of the most recent satellite based digital elevation models of Egypt. NRIAG J Astron Geophys. 2017. https://doi.org/10.1016/j.nrjag.2017.10.006.

24. Sande B, Lansen J, Hoyng C. Sensitivity of coastal flood risk assessment to digital elevation models. Water. 2012;4:568-79.

25. Hassan A, Hassaan M. Potential impact of sea level rise on the geomorphology of Kuwait state coastline. Arab J Geosci. $2020 ; 13: 1139$. https://doi.org/10.1007/s12517-020-06084-1.

26. Survey Research Institute. Final report of the research study of management plan of the costal areas over the Mediterranean sea from Port Said to Alexandria. Internal Report. Egypt: SRl; 2018.

27. Soliman A, Han L. Effects of vertical accuracy of digital elevation model (DEM) data on automatic lineaments extraction from shaded DEM. Adv Space Res. 2019;64:603-22. 
28. Abou Samra R. The use of cartographic modelling to assess the impacts of costal flooding: a case study of Port Said governorate Egypt. Environ Monit Assess. 2017;189:435. https://doi.org/10.1007/s10661-017-6152-7.

29. Hasan E, Khan S, Hong Y. Investigation of potential sea level rise impact on the Nile delta, Egypt using digital elevation models. Environ Monit Assess. 2015. https://doi.org/10.1007/s10661-015-4868-9.

30. Ebaid H. Accuracy enhancement of SRTM and ASTER DEMs using weight estimation regression model. Int J Res Eng Tech. 2014;8:371-7.

31. Elkhrachy I. Vertical accuracy assessment for SRTM and ASTER digital elevation models: a case study of Najran city, Saudi Arabia. Ain Shams Eng J . 2017. https://doi.org/10.1016/j.asej.2017.01.007.

32. Pawluszek K. Landslide features identification and morphology investigation using high-resolution DEM derivatives. Nat Hazards. 2019;96:311-30. https://doi.org/10.1007/s11069-018-3543-1.

Publisher's Note Springer Nature remains neutral with regard to jurisdictional claims in published maps and institutional affiliations. 